Proc. XIX International School of Semiconducting Compounds, Jaszowiec 1990

\title{
AMORPHOUS HYDROGENATED SILICON FILMS STUDIED BY SCHOTTKY BARRIER METHOD
}

\author{
A. Kolodziej and T. Pisarkiewicz
}

Academy of Mining and Metallurgy, Institute of Electronics, al.Mickiewicza 30, 30-059

Kraków, Poland

The problem of the effective ohmic junction and the question of the barrier height for thin film structures of $\mathrm{Al} / \mathrm{a}-\mathrm{Si}: \mathrm{H} / n^{+} \mathrm{c}-\mathrm{Si} / \mathrm{Al}$ and $\mathrm{Al} / \mathrm{a}-\mathrm{Si}: \mathrm{H} / n^{+} \mathrm{c}-$ -Si/Mo are studied. Current-voltage and temperature characteristics were measured and possible mechanisms of conductivity were extracted and discussed.

\section{PACS numbers: $72.80 . \mathrm{Ng}$}

For several years authors have been making series of technological experiments with a-Si:H films on glass substrate by d.c. magnetron sputtering. The main intention of the research is to obtain large area solar cells and a matrix of thin film transistors for liquid crystal displays [1-3].

This study is a part of series of experiments in which the problem of the effective ohmic junction and the question of the barrier height in the thin film structures are investigated. Various types of sandwich structures were prepared, as shown in the Table. D.c. magnetron sputtering was used to obtain the structures and all the films. D.c. planar magnetron system was specially made to optimize the preparation conditions of the a-Si:H films as well as hydrogen partial pressure $p_{\mathrm{H}_{2}}$, argon partial pressure $p_{\mathrm{Ar}}$, substrate temperature $T_{\mathbf{s}}$, input power $P$ and substrate bias $V_{\mathrm{s}}$. The a-Si:H films were obtained in the conditions earlier reported in $[1,2]$.

Schottky diodes were fabricated in a sandwich structure. Molybdenum or aluminum sputtered onto glass substrate, served as the back contact. An ohmic contact characterized by effective electron injection to a-Si:H, was only obtained if additional film of $0.3 \mu \mathrm{m}$ polycrystalline silicon was sputtered in an $99 \%$ of argon and $1 \%$ of phosphin atmosphere. Then, the a-Si:H film and top Schottky electrode were deposited on the substrate. Active area of the junction was $0.005 \mathrm{~cm}^{2}$.

Diode rectification ratios about $10^{4}$ are observed at room temperature, as shown in Fig. 1. This ratio is ultimately limited by the series resistance of the quasi-neutral region which affects the forward current. The undoped hydrogenated silicon is highly resistive with $\varrho \approx 10^{9} \Omega \mathrm{cm}$. The rectification ratio about $10^{4}$ was 


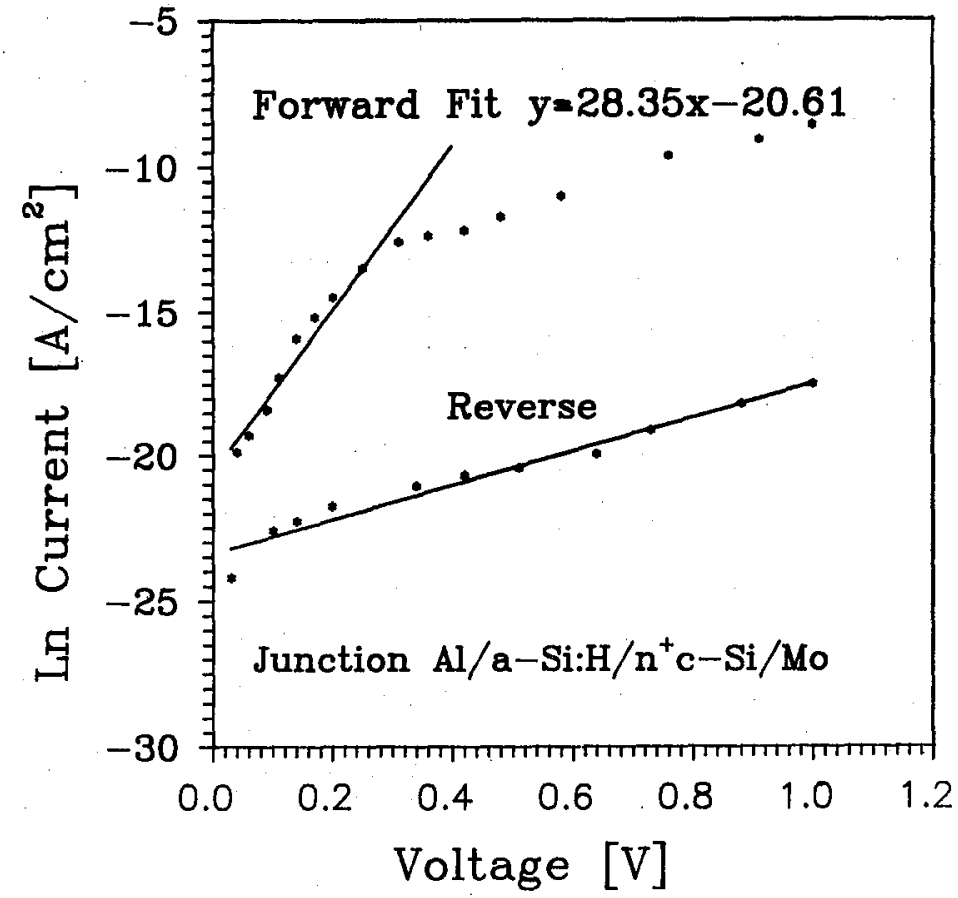

Fig. 1. Current-voltage characteristic of $\mathrm{Al} / \mathrm{a}-\mathrm{Si}: \mathrm{H} / \mathrm{Mo}$ Schottky-barrier diode at room temperature.

obtained only for sandwiches depicted as 4, as shown in the Table and in Fig. 1. The current-voltage data are examined by considering the device current as a function of both the voltage across the depletion-layer region $V_{j}$ and the voltage across the quasi-neutral region, or bulk, $V_{\mathbf{B}}$. For the former

$$
I=I_{0} \exp \left(e V_{j} / n k T\right) \times\left[1-\exp \left(-q V_{j} / k T\right)\right]
$$

or for $V_{j}>3 k T / q$

$$
I=I_{0} \exp \left(e V_{j} / n k T\right)
$$

where $n$ is the diode correction function, $T$ - the temperature, $k$ - the Boltzmann constant, and $I_{0}$ - the saturation current. The two voltages $V_{j}$ and $V_{\mathrm{B}}$ were separated as follows. First, the values of $I_{0}$ and $n$ were determined from the linear portion of a plot of $\log I$ versus applied voltage. Then for any current, the junction voltage is found

$$
V_{j}=n k T / e \times \ln \left(I / I_{0}\right)
$$

and next the bulk voltage is $V_{\mathrm{B}}=V_{\text {applied }}-V_{j}$. The currents as functions of the junction voltage and the temperature are shown in Fig. 2. 


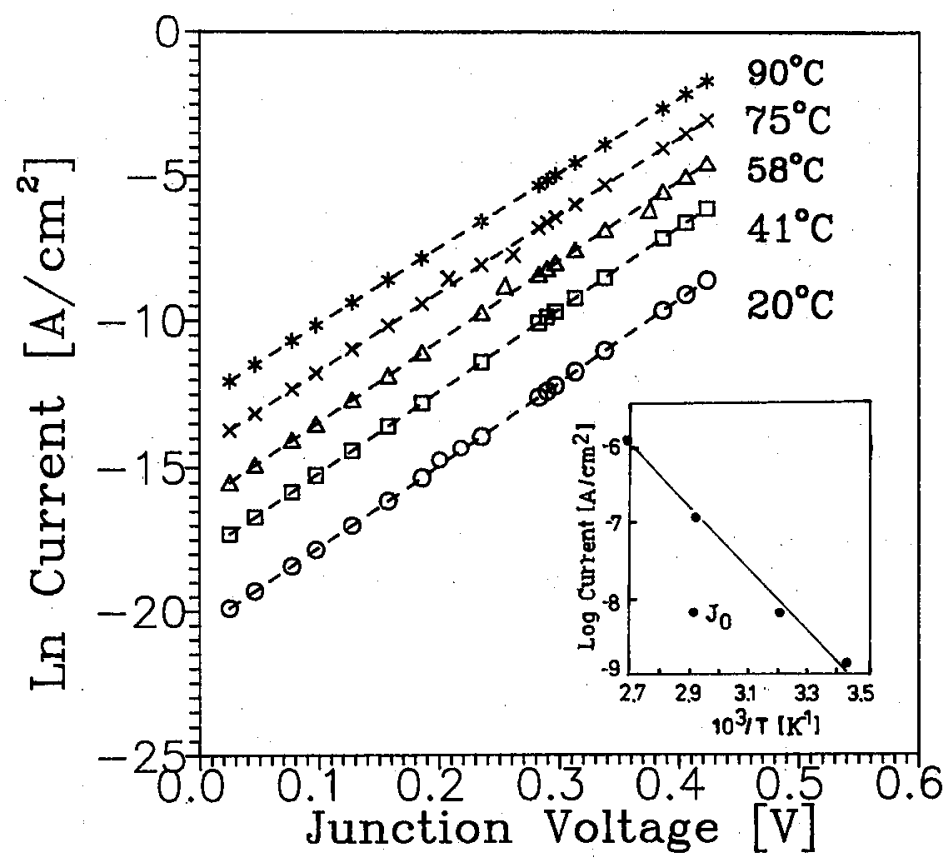

Fig. 2. Logarithm of forward current density as a function of junction voltage and temperature dependence of saturation current $J_{0}$.

Table

The structures of studied sandwiches and the results of measurements.

\begin{tabular}{c|c|c|c|c|c}
\hline \hline $\begin{array}{c}\text { ohmic } \\
\text { electrode }\end{array}$ & $\begin{array}{c}\text { additional } \\
\text { film }\end{array}$ & $\begin{array}{c}\text { intrinsic } \\
\text { material }\end{array}$ & $\begin{array}{c}\text { top } \\
\text { metal }\end{array}$ & $\begin{array}{c}\text { barrier } \\
\text { height }\end{array}$ & $\begin{array}{c}\text { temper. } \\
\text { activation } \\
\text { energy of } \\
\text { a-Si:H }\end{array}$ \\
\hline $\mathrm{Al}$ & & $\mathrm{a}$ & & & \\
$T_{\mathrm{s}}=200^{\circ} \mathrm{C}$ & - & $T_{\mathrm{s}}=250^{\circ} \mathrm{C}$ & $T_{\mathrm{s}}=150^{\circ} \mathrm{C}$ & & \\
$d=3000 \AA$ & & $d=5000 \AA$ & $d=3000 \AA$ & & \\
\hline $\mathrm{Al}$ & $n^{+}$poly Si & a-Si:H & $\mathrm{Al}$ & $\approx 0.7 \mathrm{eV}$ & $\approx 0.6 \mathrm{eV}$ \\
$T_{\mathrm{s}}=200^{\circ} \mathrm{C}$ & $T_{\mathrm{s}}=400^{\circ} \mathrm{C}$ & $T_{\mathrm{s}}=250^{\circ} \mathrm{C}$ & $T_{\mathrm{s}}=150^{\circ} \mathrm{C}$ & & \\
$d=3000 \AA$ & $d=3000 \AA$ & $d=5000 \AA$ & $d=3000 \AA$ & & \\
\hline $\mathrm{Al}$ & $n^{+}$poly Si & a-Si:H & $\mathrm{Al}$ & $\approx 0.74 \mathrm{eV}$ & $\approx 0.62 \mathrm{eV}$ \\
$T_{\mathrm{s}}=200^{\circ} \mathrm{C}$ & $T_{\mathrm{s}}=400^{\circ} \mathrm{C}$ & $T_{\mathrm{s}}=250^{\circ} \mathrm{C}$ & $T_{\mathrm{s}}=20^{\circ} \mathrm{C}$ & & \\
$d=3000 \AA$ & $d=3000 \AA$ & $d=5000 \AA$ & $d=3000 \AA$ & & \\
\hline $\mathrm{Mo}$ & $n^{+}$poly Si & $\mathrm{a}-\mathrm{Si}: \mathrm{H}$ & $\mathrm{Al}$ & $\approx 0.79 \mathrm{eV}$ & $\approx 0.63 \mathrm{eV}$ \\
$T_{\mathrm{s}}=200^{\circ} \mathrm{C}$ & $T_{\mathrm{s}}=400^{\circ} \mathrm{C}$ & $T_{\mathrm{s}}=250^{\circ} \mathrm{C}$ & $T_{\mathrm{s}}=20^{\circ} \mathrm{C}$ & & \\
$d=3000 \AA$ & $d=3000 \AA$ & $d=5000 \AA$ & $d=3000 \AA$ & &
\end{tabular}


Our observations of a series resistance effect are consistent with the discussion by Wronski et al. [4].

At room temperature the diode quality factor $n$ is 1.2 and $I_{0}$ is $1.1 \times 10^{-9} \mathrm{~A} / \mathrm{cm}^{2}$.

The diffusion theory of the Schottky barrier is preferred, in our case, to the thermionic theory because of the very short mean free path of current carriers in amorphous materials. According to the diffusion theory, the quantity $I_{0}$ is given by

$$
I_{0}=e \mu N_{\mathrm{c}} E_{\mathrm{s}} \exp \left(-e \phi_{\mathrm{B}} / k T\right),
$$

where $\mu$ is the electron mobility, $E_{\mathrm{s}}$ is the surface electric field, $N_{c}$ is the effective density of extended band states and $\phi_{B}$ is the metal-semiconductor barrier height [4-6].

Using this method, we computed the values of the barrier height $\phi_{\mathrm{B}}$ as shown in Fig. 2 and in the Table, for various types of sandwiches.

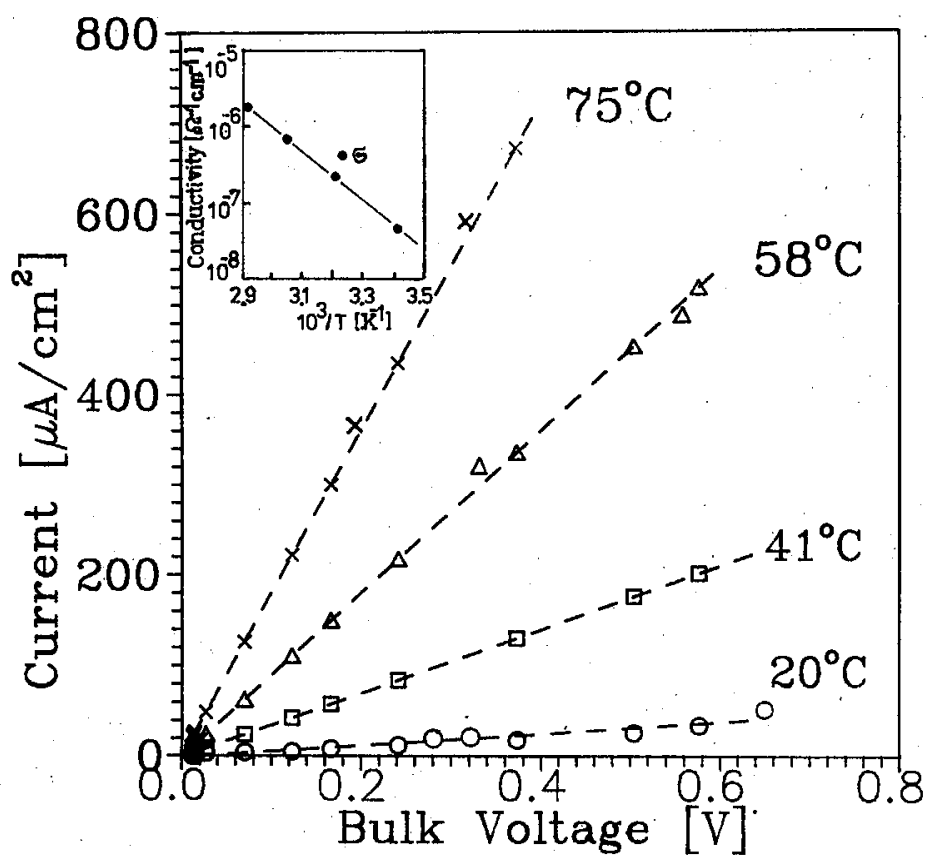

Fig. 3. Forward current density as a function of bulk voltage and temperature dependence of the bulk conductivity $\sigma$.

Figure 3 shows that the relationship between current and bulk voltage is ohmic. Slight nonlinearity for voltages greater than $0.5 \mathrm{~V}$ suggestive of space-charged limited current is observed.

From initial part of the fits shown in Fig. 3, one may obtain the conductivity 


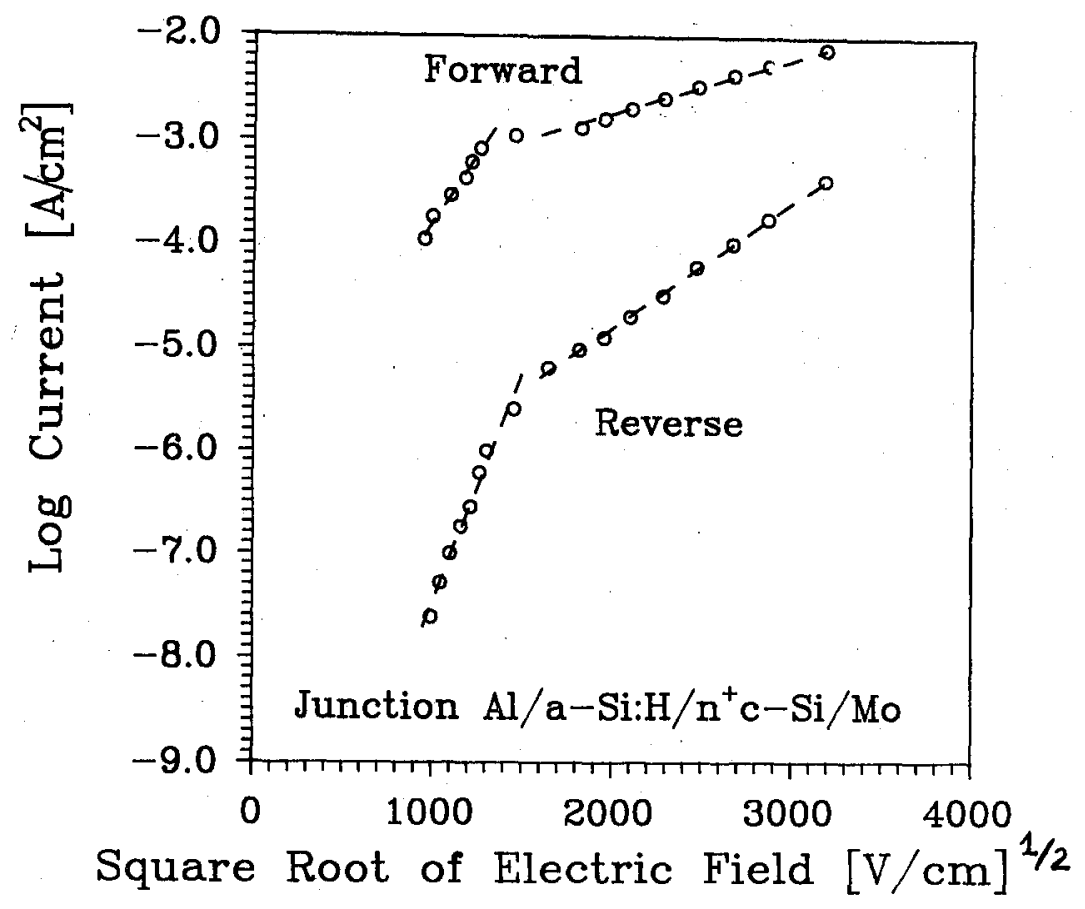

Fig. 4. Forward and reverse current density as functions of the square root of electric field for voltages greater than $1 \mathrm{~V}$.

versus temperature plot. The conductivity gives a simple temperature activation, characteristic of semiconductors

$$
\sigma=\sigma_{0} \exp \left(-E_{a} / k T\right) .
$$

The diode reverse current does not saturate at $I_{0}$, but increases smoothly with applied voltage. The data does not fit a simple power law and does not fit simple models of reverse bias behaviour.

Figure 4 shows logarithm of forward and reverse current density as functions of the square root of electric field for voltages greater than $1 \mathrm{~V}$. Two levels of fit can be seen, indicating at least two mechanisms of conductivity where the logarithm of current depends on the square root of electric field. That feature is characteristic of both forward and reverse bias indicating that the conductivity mechanism is rather bulk limited. The kind of dependence suggests that the conductivity is limited by Poole-Frenkel mechanism. Amorphous silicon is considered as having a lot of localized states in the gap and in the band tails. Two slopes, as seen in Fig. 4, could be connected with field emission from band tail traps to the conduction band and with field assisted hopping between localized states within the band. 


\section{References}

[1] A. Kolodziej, S. Nowak, Thin Solid Films 175, 37 (1989).

[2] A. Kołodziej, T. Pisarkiewicz, Acta Phys. Pol. A73, 495 (1988).

[3] A. Kolodziej, AGH Press, Kraków, Vol. 8, 3 (1989).

[4] C.R. Wronski, D.E. Carlson, R.E. Daniel, Appl. Phys. Lett. 29, 602 (1976).

[5] W. Paul, A.J. Lewis, G.A.N. Connell, T.D. Moustakas, Solid State Commun. 20, 969 (1976).

[6] N.F. Mott, E.A. Davis, Electronic Processes in Non-Crystalline Materials, 2nd ed., Clarendon Press, Oxford 1979, p. 215. 